\section{(2) \\ BRAZIILIAN JOURNAL \\ OF MEDICAL AND BIOLOGICAL RESEARCH}

www.bjournal.com.br
ISSN 0100-879X

Volume 45 (5) 376-472 May 2012

BIOMEDICAL SCIENCES

AND

CLINICAL INVESTIGATION

Braz J Med Biol Res, May 2012, Volume 45(5) 392-400

doi: 10.1590/S0100-879X2012007500058

Mechanisms of endothelial dysfunction in obesity-associated hypertension

N.S. Lobato, F.P. Filgueira, E.H. Akamine, R.C. Tostes, M.H.C. Carvalho and Z.B. Fortes

The Brazilian Journal of Medical and Biological Research is partially financed by

\section{Q QNPPq}

Ministério

da Ciência e Tecnologia

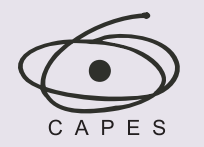

Ministério da Educação

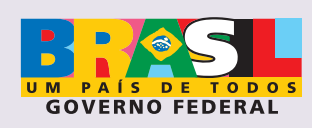

DTFAPESP

Institutional Sponsors

๑ SHIMADZu

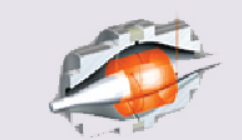

lore High - Performance MS Orbitrap Technology

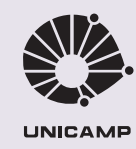
andilicica Thermo 


\title{
Mechanisms of endothelial dysfunction in obesity-associated hypertension
}

\author{
N.S. Lobato ${ }^{1,3}$, F.P. Filgueira ${ }^{1}$, E.H. Akamine ${ }^{1}$, R.C. Tostes ${ }^{2}$, \\ M.H.C. Carvalho ${ }^{1}$ and Z.B. Fortes ${ }^{1}$ \\ ${ }^{1}$ Departamento de Farmacologia, Instituto de Ciências Biomédicas, \\ Universidade de São Paulo, São Paulo, SP, Brasil \\ 2Departamento de Farmacologia, Faculdade de Medicina de Ribeirão Preto, \\ Universidade de São Paulo, Ribeirão Preto, SP, Brasil \\ ${ }^{3}$ Departamento de Ciências Biológicas, Universidade Federal de Goiás, Jataí, GO, Brasil
}

\begin{abstract}
Obesity is strongly associated with high blood pressure, dyslipidemia, and type 2 diabetes. These conditions synergistically increase the risk of cardiovascular events. A number of central and peripheral abnormalities can explain the development or maintenance of high blood pressure in obesity. Of great interest is endothelial dysfunction, considered to be a primary risk factor in the development of hypertension. Additional mechanisms also related to endothelial dysfunction have been proposed to mediate the development of hypertension in obese individuals. These include: increase in both peripheral vasoconstriction and renal tubular sodium reabsorption, increased sympathetic activity and overactivation of both the renin-angiotensin system and the endocannabinoid system and insulin resistance. The discovery of new mechanisms regulating metabolic and vascular function and a better understanding of how vascular function can be influenced by these systems would facilitate the development of new therapies for treatment of obesity-associated hypertension.
\end{abstract}

Key words: Hypertension; Obesity; Endothelial dysfunction; Oxidative stress; Renin-angiotensin system; Nitric oxide

\section{Introduction}

Obesity is a major worldwide public health problem $(1,2)$, especially in the United States, where approximately 300,000 deaths each year have been attributed to overweight or obesity. The worldwide prevalence of obesity has rapidly risen to epidemic proportions in the past decades, not only in industrialized nations but also in developing countries $(1,2)$. Current estimates indicate that more than 1 billion people in the world are overweight or obese, compared to 850 million who are underweight (3). In the United States, obesity continues to be a leading public health concern. At least $65 \%$ of adults are overweight, and approximately onethird of adults are obese with a body mass index (defined as $\mathrm{kg}$ weight $/ \mathrm{m}^{2}$ height) of more than 30 (1). An alarming increase in the prevalence of obesity has also been observed in Brazil. When data from the 1970s showed undernutrition as the main nutritional problem in Brazil, obesity was still considered a minor issue. With time, this scenario has changed dramatically, with a strong reduction of undernutrition and the prevalence of obesity constantly growing in the Brazilian population: from $5.7 \%$ in $1974 / 1975$ to $9.6 \%$ in 1989 , to $11.4 \%$ in 2006 , and then to $13.9 \%$ in 2009 $(4,5)$. Changes in the quality, quantity and source of food consumed, combined with a decrease in levels of physical activity among the genetically predisposed population, have led to the increased prevalence of obesity (3).

Associated with obesity is hypertension, considered as the primary mediator of the development of obesity-induced cardiovascular diseases (6). Clinical and experimental studies have consistently indicated that excess weight predicts the development of hypertension $(7,8)$. Although the importance of obesity as a cause of hypertension is well established, the excess weight-induced physiological and molecular mechanisms that mediate high blood pressure are only beginning to be elucidated. Several mechanisms with therapeutic implications as potential causes of obesityinduced hypertension have been identified in the last few years. Of great interest are observations on endothelial dysfunction in obesity, which could contribute to hyperten-

Correspondence: Z.B. Fortes, Departamento de Farmacologia, Instituto de Ciências Biomédicas, USP, 05508-900 São Paulo, SP, Brasil. Fax: +55-11-3091-7317. E-mail: zbfortes@icb.usp.br

Received July 13, 2011. Accepted April 2, 2012. Available online April 13, 2012. Published May 7, 2012. 
sion. It is well established that obesity impairs the vasodilating properties of the endothelium leading to endothelial dysfunction (9), which in turn can be considered to be the first step in the progression of cardiovascular disease (6).

Additional mechanisms, still related to endothelial dysfunction, have been proposed to mediate hypertension in obese patients. These include: increase in both peripheral vasoconstriction and renal tubular sodium reabsorption, increased sympathetic activity, overactivation of the reninangiotensin system (RAS), and insulin resistance (Figure 1). The intra-abdominal visceral deposition of adipose tissue is also considered to be a contributor to the development of hypertension in obese individuals $(7,8)$. In addition to these advances, a revolution in our understanding of mechanisms regulating appetite, metabolism, and adiposity has occurred since the discovery of the endocannabinoid system more than 10 years ago $(10,11)$. This system is activated in obese individuals and might mediate the effects of obesity on the development of the metabolic and vascular alterations of hypertension.

If these advances can translate into safe and effective pharmacological treatment of obesity, this would also greatly impact the management of obesity-associated hypertension. Considering this, in the present section, an overview of the advances in the understanding of the pathophysiology of obesity-associated hypertension, focusing on the role of endothelial dysfunction, will be addressed. We also outline the function of the main modulating systems of the development of hypertension and obesity. A better understanding of how the vascular function can be influenced by these systems would facilitate therapeutic approaches to the treatment of obesity-associated hypertension.

\section{Endothelial dysfunction: linking obesity and hypertension}

The vascular endothelium plays an important role in the control of vascular homeostasis. Besides providing a physical barrier between the lumen and the vessel wall, the endothelium actively regulates the basal vascular tone and reactivity in physiological conditions (12). Endothelial dysfunction, represented by an altered ability of the endothelium to maintain vascular homeostasis through the release of endothelium-derived relaxing factors and endotheliumderived contracting factors, is present in human obesity and associated comorbidities (12), promoting changes in pressure and flow patterns and, consequently, resulting in obesity-associated hypertension. Even in normotensive subjects, endothelial function progressively deteriorates as blood pressure rises (13).

Endothelial dysfunction is an important risk factor for hypertension because it leads not only to functional alterations, represented by the impaired control of the vascular tonus, but also to structural changes, such as thickening of the intima and media of the vessel wall. The association between endothelial dysfunction and increased blood pressure in obesity comes from studies showing that obese individuals display blunted vasodilatation in response to classical endotheliumdependent vasodilators such as acetylcholine in resistance arteries, as well as reduced capillary recruitment in response to reactive hyperemia and shear stress $(13,14)$ and that the severity of endothelial dysfunction

Figure 1. Mechanisms involved in obesity-associated hypertension. WAT = white adipose tissue; SNS = sympathetic nervous system; RAS = renin-angiotensin system. 
correlates with the degree of visceral adiposity (14).

Although the mechanisms linking obesity with endothelial dysfunction have not yet been fully clarified, several factors have been proposed to mediate this process (Figure 2). Results obtained with experimental models of obesityassociated hypertension indicate a potential role for vascular proinflammatory factors and oxidative stress on endothelial dysfunction in this condition. Mice with high-fat diet-induced obesity display increased blood pressure and impairment in the relaxation of the aorta in response to acetylcholine, an endothelium-dependent vasodilator. The endothelial dysfunction in this model has been proposed to be a consequence of the reduced antioxidant defense and the local activation of the nuclear factor $\mathrm{KB}$ (NF-KB) pathway (15). In a model of hypertension without obesity, high activation of $\mathrm{NF}-\mathrm{KB}$ and increased superoxide $\left(\mathrm{O}_{2}^{-}\right)$generation are observed in the vascular wall (16), indicating that these two factors may be the link between obesity and hypertension.

Decreased nitric oxide (NO) bioavailability has been reported to play a major role in endothelial dysfunction in obesityassociated hypertension $(17,18)$. High $\mathrm{O}_{2}$ - levels as a consequence of increased generation of reactive oxygen species (ROS) or reduced antioxidant defense contribute to decreasing NO bioavailability. Endothelial nitric oxide synthase (eNOS) uncoupling, a process in which eNOS generates $\mathrm{O}_{2}^{-}$instead of NO when the concentrations of either L-arginine, the substrate of NOS, or tetrahydrobiopterin $\left(\mathrm{BH}_{4}\right)$, a cofactor of the enzyme, are depleted, may also mediate decrease in NO bioavailability (19). The crucial role of uncoupled eNOS as a $\mathrm{O}_{2}^{-}$producing enzyme has been reported in hypertension (19) and diabetes (20). In a model of obesity without high blood pressure or hyperglycemia, the detrimental impact of obesity on endothelial function in the microvasculature is also attributable to the reduced NO bioavailability as a consequence of uncoupled eNOS (21). These findings indicate the presence of uncoupled eNOS in obesity as a primary event before the establishment of comorbidities.

Another factor that has been suggested to be associated with the increased generation of ROS in obesity and hypertension is the enzyme $\mathrm{NAD}(\mathrm{P}) \mathrm{H}$ oxidase (the main source of $\mathrm{O}_{2}$ - in the vasculature). Excessive $\mathrm{O}_{2}{ }^{-}$generation from AT1-dependent overexpression of $\mathrm{NAD}(\mathrm{P}) \mathrm{H}$-oxidase subunits was demonstrated in spontaneously hypertensive rats (22). In a similar way, increased $\mathrm{O}_{2}^{-}$derived from $\mathrm{NAD}(\mathrm{P}) \mathrm{H}$ oxidase was found to impair the endothelial function of the aorta from Zucker fa/fa rats, a model of obesity and insulin resistance (23).

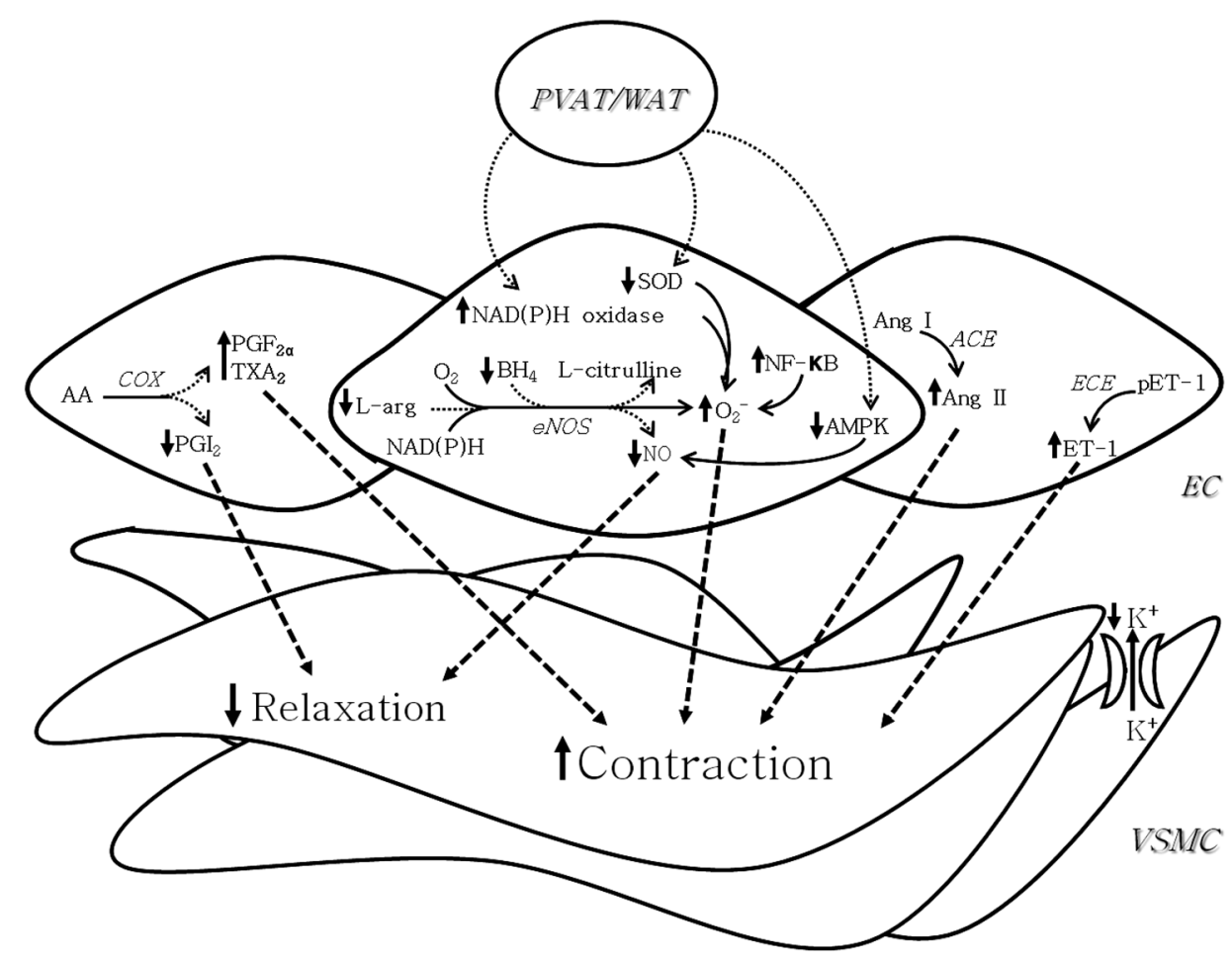

Figure 2. Putative mechanisms of endothelial dysfunction in obesity-associated hypertension. Decreased nitric oxide (NO) bioavailability as a consequence of uncoupled endothelial nitric oxide synthase (eNOS), a process in which eNOS generates superoxide $\left(\mathrm{O}_{2}^{-}\right)$instead of $\mathrm{NO}$ when the concentrations of either L-arginine (L-arg), the substrate of NOS, or tetrahydrobiopterin $\left(\mathrm{BH}_{4}\right)$, a cofactor of the enzyme, are depleted, may mediate endothelial dysfunction in obesity-associated hypertension. Increased reactive oxygen species generation as a consequence of increased NF oxidase and NF$\mathrm{KB}$ activity and reduced superoxide dismutase (SOD) activity also contribute to decreasing NO bioavailability in this situation. Increased production of endothelium-derived contractile factors (EDCFs), including prostanoids $\left(\mathrm{PGF}_{2 \alpha}\right.$ and $\mathrm{TX}_{2}$ ), angiotensin II (Ang II) and endothelin I (ET-1) constitute additional mechanisms involved in endothelial dysfunction in obesity-associated hypertension. A potential role for perivascular adipose tissue (PVAT) in the vascular dysfunction of obesity has also been proposed. PVAT can reduce adenosine monophosphate-activated protein kinase (AMPK) activation and increase the $\mathrm{NAD}(\mathrm{P}) \mathrm{H}$ oxidase-induced $\mathrm{O}_{2}$ - production leading to reduced $\mathrm{NO}$ production. $\mathrm{AA}=$ arachidonic acid; $\mathrm{ACE}=$ angiotensin-converting enzyme; $\mathrm{COX}=$ cyclooxygenase $\mathrm{EC}=$ endothelial cells; $\mathrm{ECE}=$ endothelin-converting enzyme; NF-kB = nuclear factor $\mathrm{kB} ; \mathrm{pET}-1$ = pro-endothelin 1 ; $\mathrm{PGI}_{2}=$ prostaglandin $\mathrm{I}_{2} ; \mathrm{VSMC}=$ vascular smooth muscle cells; WAT = white adipose tissue. 
An additional mechanism involved in vascular dysfunction in obesity is the disturbance in the vascular profile of prostanoid release. Overproduction of vasoconstrictor prostanoids has been reported in obesity-associated comorbidities such as diabetes (24). In addition, thromboxane $\mathrm{A} 2$ and prostaglandin $\mathrm{H} 2\left(\mathrm{TXA}_{2} / \mathrm{PGH}_{2}\right)$ receptor expression is enhanced in obesity-associated hypertension (25). $A$ reduced balance of $P \mathrm{Cl}_{2}$ and $T X A_{2}$ release as a result of the increased $\mathrm{TXA}_{2}$ and decreased $\mathrm{PGI}_{2}$ levels was recently reported in obese rats (21). This alteration has been proposed to be associated with increased conversion of arachidonic acid to prostaglandins by cyclooxygenase- 2 (COX2), an isoform of COX described to be induced specifically under inflammatory conditions (21).

Increased production or activity of other vasoconstrictor substances, such as endothelin-1 (ET-1) and angiotensin II (Ang II), is also implicated in endothelial dysfunction in obesity and hypertension $(26,27)$. In hypertensive patients, increased body mass is associated with enhanced ET-1induced vasoconstriction (17), suggesting that this abnormality is a potential mechanism for endothelial dysfunction and may play a role in the pathophysiology of obesity-related hypertension.

A potential role for perivascular adipose tissue in the vascular dysfunction occurring in obesity has also been proposed. Recent studies have demonstrated that the adipose tissue surrounding blood vessels is a functional component of the vasculature, modulating vascular reactivity and proliferation $(18,28,29)$. It has been demonstrated that, under physiological conditions, the perivascular fat attenuated the vascular responsiveness to several constrictor agonists, including serotonin, phenylephrine, and ET-1. This effect was attributable to the activation of voltage-dependent, delayed-rectifier $\mathrm{K}^{+}(\mathrm{Kv})$ channels that hyperpolarize the vascular smooth muscle cell membrane (18). Furthermore, it has been shown that perivascular adipose tissue releases relaxation factors in different vascular beds $(18,30)$. Although these findings do not provide an explanation for the association between obesity and hypertension, recent studies have shown that the ability of the perivascular adipose tissue to release relaxation factors is impaired in experimental models of obesity (31). Additionally, it has been shown that perivascular adipose tissue impacts vascular function and remodeling through impairment of both eNOS-mediated vasodilatation and the AMP-activated protein kinase/mammalian target of rapamycin (AMPK/mTOR) pathway in rats with high-fat diet-induced obesity (32). Perivascular adipose tissue has also been shown to enhance the contractile response of superior mesenteric arteries from Wistar-Kyoto rats through the production of superoxide mediated by NAD $(P) H$ oxidase, and this enhancement involves activation of tyrosine kinase and the MAPK/ERK pathway (33). On this basis, perturbations in perivascular adipose tissue regulation of vascular reactivity may contribute to blood pressure elevation in obesity-related hypertension.

Based on the observations discussed above, it is clear that the endothelium is a major regulator of vascular reactivity, maintaining the balance between vasodilatation and vasoconstriction. Disturbance in this balance leading to endothelial dysfunction is considered an early marker for the development of cardiovascular diseases. Not surprisingly, this integral role of the endothelium in vascular health and endothelial dysfunction in obesity has generated considerable interest in its potential role for the development of obesity-associated hypertension. Of relevance, although the effects of perivascular adipose tissue on the vasculature in the presence of obesity still constitutes a major challenge, it is well known that this tissue is implicated in the regulation of vascular function in the physiological state. Thus, the perivascular adipose tissue also provides an opportunity to understand how changes in the regulation of vascular function can contribute to the development of hypertension in obesity.

\section{Role of insulin resistance in endothelial dysfunction in obesity-associated hypertension}

Obesity is frequently associated with insulin resistance and compensatory hyperinsulinemia. Clinical and experimental studies suggest a potential cause-effect relationship between obesity and insulin resistance, since weight gain or weight loss is closely correlated with reduction/increase in insulin sensitivity, respectively $(34,35)$. Insulin resistance in obesity contributes to a range of metabolic and cardiovascular alterations, which would favor the development of hypertension (36).

Insulin is essential for normal tissue development, maintaining glucose homeostasis and regulating carbohydrate, lipid, and protein metabolism (37). This hormone also has important vascular actions, which include the stimulation of endothelium-dependent NO release, leading to vasodilatation and increased blood flow, favoring glucose uptake by skeletal muscle. Another distinct insulin-signaling pathway in the endothelium is the regulation of the release of the vasoconstrictor peptide ET-1 (38). The vascular actions of insulin play a central role in the control of metabolic and hemodynamic homeostasis under healthy conditions.

The role of insulin resistance in the physiopathology of hypertension was confirmed by studies showing that non-obese insulin-resistant patients display the same prevalence of hypertension when compared to obese individuals $(36,39)$.

The influence of insulin on endothelial function has been extensively studied. It was demonstrated that the effect of vasodilating agents on endothelial cells depends on a direct facilitator action of insulin and that in insulin-deficient states, early alterations of the effects of insulin on endothelial cells might contribute to the impaired reactivity of the microves- 
sels (40). Consistent with these results are the observations that treatment with either insulin (20) or the insulin sensitizer metformin (41) corrects the reduced endothelium-dependent vasodilatation without fully improving the metabolic parameters of experimental models of diabetes. Impaired arteriole and venule responses to endothelium-dependent vasodilators in type 2 diabetes are also corrected by both acute and chronic insulin treatment (42).

Decreased sensitivity of resistance vessels to endothelium-dependent vasodilatation induced by insulin has also been observed in obese individuals (43). Clinical studies have demonstrated a 40 to $50 \%$ reduction in endotheliumdependent vasodilatation induced by insulin in non-diabetic and diabetic obese patients. This alteration was attributed to the impaired ability of insulin to stimulate NO production by endothelial cells (44). These observations indicate that obesity and insulin resistance, independently of other risk factors, are associated with impairment of endothelial function.

Among the mechanisms proposed to mediate the role of insulin in the association between obesity and hypertension is insulin resistance in vascular smooth muscle cells, with impairment of insulin-mediated ion exchange processes $\left(\mathrm{Ca}^{2+}\right.$-ATPase and $\mathrm{Na}^{+}, \mathrm{K}^{+}$-ATPase), leading to $\mathrm{Ca}^{2+}$ and $\mathrm{Na}^{+}$accumulation on the vascular wall $(45,46)$. This alteration facilitates the action of vasoconstrictor agents such as Ang II and norepinephrine (47). Insulin resistance in experimental models of hypertension is also accompanied by endothelial dysfunction in resistance vessels with impaired PI3-kinase-dependent NO production and enhanced ET-1 secretion, which may combine with elevated peripheral vascular resistance and contribute to hypertension in this model (38). Taken together, these findings support a role for several related mechanisms by which insulin resistance might contribute to the development of endothelial dysfunction in obesity-associated hypertension.

\section{Sympathetic nervous system and endothelial dysfunction in obesity-associated hypertension}

The overactivity of the sympathetic nervous system is a common feature of obesity, and is closely associated with the cardiovascular and renal alterations observed in this condition (48). A number of factors may account for this, including baroreflex dysfunction, hypothalamus-pituitary axis dysfunction, insulin resistance, hyperinsulinemia, hyperleptinemia, and overactivity of the RAS. Weight loss reduces blood pressure and the activity of the sympathetic nervous system (49), confirming that long-term sympathoactivation is the link between obesity and the increase in blood pressure (Figure 1).

Leptin has emerged as a link between excess adiposity and increased cardiovascular sympathetic activity. Besides having an effect on appetite and metabolism, leptin acts on the hypothalamus to increase blood pressure through activation of the sympathetic nervous system (50). Obesity is usually associated with selective leptin resistance, a condition characterized by resistance to the feeding and weight reducing effects of leptin, but preservation of the renal sympathoactivation by this hormone (51). Hyperinsulinemia may also play a role in the overactivity of the sympathetic nervous system in obesity. Insulin, like leptin, causes sympathetic activation in different tissues, including the kidney (52). The ability of insulin to stimulate renal sympathetic outflow is preserved in experimental models of obesity, despite the insulin resistance observed in this condition (53). The elevated circulating levels of non-esterified fatty acid (NEFA) from visceral fat depots in obese subjects appear also to mediate the increased sympathetic activity and, ultimately, the raise in blood pressure (54). Longitudinal and cross-sectional studies also indicate a role for some newly discovered peptides such as ghrelin (55) and adiponectin (56), as independent risk factors for hypertension in obese patients via modulation of the sympathetic nervous system.

Interactions between autonomic nervous system regulation and endothelial function may provide a mechanism to explain the endothelial dysfunction occurring in obesity and hypertension (Figure 1). The sympathetic nervous system may directly influence the endothelium. Endothelial cells possess both $\alpha 2$-adrenoceptors and $\beta$-adrenoceptors (57). Given that activation of endothelial adrenergic receptors releases endothelium-derived relaxant factors like NO and endothelium-derived contracting factors such as ET-1 $(57,58)$, disturbances in the balanced release of these factors as a consequence of altered activity of the sympathetic nervous system may explain the role of this system in abnormalities of endothelial function in obesity-associated hypertension (44). The best evidence of this comes from studies showing that exaggerated sympathetic nervous system activation may impair endothelial function and enhance an endothelium-mediated atherogenic process (59). Increased levels of catecholamines are also postulated to induce macrophages into the vessel (60) and increase uptake of low-density lipoproteins by endothelial cells (61). Despite this evidence, it is unclear whether the sympathetic nervous system and endothelial systems are negatively affecting one another, or whether both systems are affected as a consequence of obesity and hypertension.

\section{Endothelial dysfunction and the RAS}

The RAS is another important system involved in hypertension in obesity (Figure 1). Increased activity of the RAS, represented by increased circulating angiotensinogen, renin, aldosterone, and angiotensin-converting enzyme (ACE) activity has been demonstrated in obesity, both systemically and within adipose tissue, and was directly related to the mass of adipose tissue $(62,63)$. The significant 
role for Ang II in stimulating sodium reabsorption, impairing renal-pressure natriuresis and causing hypertension in obesity is supported by studies showing that a modest reduction in body weight can lead to a meaningfully reduced RAS activity in plasma and adipose tissue, which parallels a reduction in blood pressure $(64,65)$. A dietary intervention study in menopausal women showed that a $5 \%$ weight loss resulted in a $7-\mathrm{mmHg}$ reduction of blood pressure. This decrease was accompanied by significant declines of serum angiotensinogen (27\%), renin (43\%) and ACE activity (12\%), as well as angiotensinogen expression in adipose tissue (20\%) (64).

Under physiological conditions, infusion of Ang II causes redirection of blood flow between different vascular beds and within the vascular bed of skeletal muscle. This effect leads to an increase in total muscle blood flow and capillary recruitment with a consequent increase in insulin-induced glucose uptake (66). However, in obesity, the RAS seems to have a detrimental effect on insulin-induced glucose uptake (65). Additionally, Ang II has been reported to impair insulin stimulation of insulin receptor substrate 1 (IRS-1) tyrosine phosphorylation and coupling of the insulin receptor pathway to PI3-kinase in the vasculature, suggesting that activation of the RAS may contribute to insulin resistance in the vasculature (67).

The activation of the RAS may also mediate endothelial dysfunction in obese individuals. Ang II activates receptors located on either endothelial or smooth muscle cells. The activation of endothelial receptors is linked to the production of the contractile peptide ET-1 and ROS. The effects of Ang II on smooth muscle cells involve contraction and proliferation (68). The role of the RAS as an independent factor involved in endothelial dysfunction in hypertension was confirmed by the observation that treatment of DOCA-salt hypertensive rats with an ACE inhibitor corrected the decreased endothelium-dependent relaxation in response to acetylcholine in aortic rings, independently of normalizing blood pressure levels (69). In addition, it was demonstrated that the free fatty acids (FFA)-induced impairment of endothelial function in obese individuals was completely prevented by either the AT1 receptor blocker or the ACE inhibitor, which suggests that an elevation of FFA induces endothelial dysfunction through activation of the RAS (70). Chronically elevated Ang II can also increase ROS generation $(16,71)$. ROS generation can reduce the endothelium-dependent vasodilatation by impairing NO bioavailability (72). Therefore, these findings indicate an important role for the RAS providing another potential link between obesity and hypertension.

\section{Endocannabinoid system: cardiovascular effects in obesity and hypertension}

The endocannabinoid system has emerged as a highly relevant topic in the scientific community because of its important role in the central and peripheral regulation of food intake and energy balance (73). In fact, it has been demonstrated that increased activity of the endocannabinoid system contributes to the increased food intake and the development of the cardiovascular risk factors that accompany weight gain (11). Since increased visceral adiposity can be considered to be the link between overweight and hypertension, a dysregulated, overstimulated endocannabinoid system in visceral adipose tissue could indirectly contribute to visceral obesity-associated hypertension $(74,75)$. However, endogenous cannabinoid ligands reduce blood pressure and heart rate and are potent vasodilators in a number of isolated vascular preparations of normotensive non-obese animals, which involve endothelium-dependent and -independent mechanisms (76-79). Thus, the direct involvement of an overstimulated endocannabinoid system in the endothelial dysfunction and hypertension occurring in obesity is not clear. Indeed, the implication of the endocannabinoid system in the vascular dysfunction of hypertension is controversial. In fact, since increased hypotensive and vasodilator effects of cannabinoids have been reported in hypertension $(80,81)$, this system could represent a compensatory mechanism to counteract the increase in arterial pressure and vascular resistance in hypertension.

The implication of the overstimulated endocannabinoid system in the endothelial dysfunction and obesity-associated hypertension has not been clarified. A dysfunctional activity of the endocannabinoid system in obesity could nullify its compensatory effect to counteract the increase in arterial pressure and endothelial dysfunction as that observed in hypertension. Therefore, a direct involvement of the overstimulated endocannabinoid system in endothelial dysfunction and obesity-associated hypertension cannot be ruled out and further studies are necessary to clarify this point.

\section{Conclusion}

Reduced NO availability as a consequence of uncoupled eNOS and increased $\mathrm{NAD}(\mathrm{P}) \mathrm{H}$ oxidase activity, and increased production of endothelium-derived contracting factors (EDCFs) (prostanoids, Ang II, and ET-1) are implicated in endothelial dysfunction in obesity-associated hypertension. Visceral adiposity and/or perivascular adipose tissue dysfunction are directly involved in $\mathrm{NO} /$ EDCFs imbalance by promoting a chronic inflammatory state. Moreover, disorders promoted by visceral adiposity dysfunction can individually impair endothelial function. Insulin resistance is the most common obesity-promoted disorder and this condition is characterized by impaired PI3-kinase-dependent NO production and enhanced ET-1 secretion, which impair the capacity of insulin to promote a facilitator action of vasodilator agents. Compensatory hyperinsulinemia due to insulin resistance, hyperleptinemia, increased activity of the RAS, among other factors, are 
responsible for the overactivity of the sympathetic nervous system in obesity-associated hypertension. Disturbances in the balanced release of $\mathrm{NO}$ and constrictor factors stimulated by activation of endothelial adrenergic receptors contribute to the endothelial dysfunction of obesity-associated hypertension. Besides promoting endothelial dysfunction through sympathetic overactivation, increased RAS activity also has a direct impact on endothelial function. Ang II, by activating receptors located on endothelial or smooth muscle cells, produces ET-1 and ROS. Finally, increased activity of the endocannabinoid system contributes to the pathophysiology of obesity; however, its contribution to the endothelial dysfunction of obesity-related hypertension has not been elucidated.

In conclusion, the mechanisms involved in the endothelial dysfunction of obesity-associated hypertension are

\section{References}

1. Ogden CL, Carroll MD, Curtin LR, McDowell MA, Tabak CJ, Flegal KM. Prevalence of overweight and obesity in the United States, 1999-2004. JAMA 2006; 295: 1549-1555.

2. Flegal KM, Carroll MD, Ogden CL, Curtin LR. Prevalence and trends in obesity among US adults, 1999-2008. JAMA 2010; 303: 235-241.

3. Yach D, Stuckler D, Brownell KD. Epidemiologic and economic consequences of the global epidemics of obesity and diabetes. Nat Med 2006; 12: 62-66.

4. Hossain P, Kawar B, El Nahas M. Obesity and diabetes in the developing world - a growing challenge. N Engl J Med 2007; 356: 213-215.

5. Schmidt MI, Duncan BB, Azevedo e Silva, Menezes AM, Monteiro CA, Barreto SM, et al. Chronic non-communicable diseases in Brazil: burden and current challenges. Lancet 2011; 377: 1949-1961.

6. Echahidi N, Mohty D, Pibarot P, Despres JP, O'Hara G, Champagne $\mathrm{J}$, et al. Obesity and metabolic syndrome are independent risk factors for atrial fibrillation after coronary artery bypass graft surgery. Circulation 2007; 116: I-213-I-219.

7. Hall JE. The kidney, hypertension, and obesity. Hypertension 2003; 41: 625-633.

8. Rahmouni K, Correia ML, Haynes WG, Mark AL. Obesityassociated hypertension: new insights into mechanisms. Hypertension 2005; 45: 9-14.

9. Jonk AM, Houben AJ, de Jongh RT, Serne EH, Schaper NC, Stehouwer CD. Microvascular dysfunction in obesity: a potential mechanism in the pathogenesis of obesity-associated insulin resistance and hypertension. Physiology 2007; 22: 252-260.

10. De Petrocellis L, Di Marzo V. An introduction to the endocannabinoid system: from the early to the latest concepts. Best Pract Res Clin Endocrinol Metab 2009; 23: 1-15.

11. Pacher P, Mukhopadhyay P, Mohanraj R, Godlewski G, Batkai S, Kunos G. Modulation of the endocannabinoid system in cardiovascular disease: therapeutic potential and limitations. Hypertension 2008; 52: 601-607.

12. Villar IC, Francis S, Webb A, Hobbs AJ, Ahluwalia A. Novel various and not mutually exclusive, and in some way they are redundant (Figure 1). The relative contribution of any of them is not easily defined. The important advances in understanding the pathophysiology of obesity-associated hypertension that have been achieved in the last years can greatly impact the prevention and the management of obesity-associated hypertension. Any intervention able to prevent or reverse obesity-related endothelial dysfunction might represent a major tool to improve the cardiovascular outcome of obese patients.

\section{Acknowlegments}

The authors are grateful to Fundação de Amparo à Pesquisa do Estado de São Paulo (FAPESP) for research support. aspects of endothelium-dependent regulation of vascular tone. Kidney Int 2006; 70: 840-853.

13. de Jongh RT, Serne EH, ljzerman RG, de Vries G, Stehouwer CD. Impaired microvascular function in obesity: implications for obesity-associated microangiopathy, hypertension, and insulin resistance. Circulation 2004; 109: 2529-2535.

14. Arcaro G, Zamboni M, Rossi L, Turcato E, Covi G, Armellini $F$, et al. Body fat distribution predicts the degree of endothelial dysfunction in uncomplicated obesity. Int $\mathrm{J}$ Obes Relat Metab Disord 1999; 23: 936-942.

15. Kobayasi R, Akamine EH, Davel AP, Rodrigues MA, Carvalho $C R$, Rossoni LV. Oxidative stress and inflammatory mediators contribute to endothelial dysfunction in high-fat diet-induced obesity in mice. J Hypertens 2010; 28: 21112119.

16. Ceravolo GS, Fernandes L, Munhoz CD, Fernandes DC, Tostes RC, Laurindo FR, et al. Angiotensin II chronic infusion induces B1 receptor expression in aorta of rats. Hypertension 2007; 50: 756-761.

17. Cardillo C, Campia U, lantorno M, Panza JA. Enhanced vascular activity of endogenous endothelin-1 in obese hypertensive patients. Hypertension 2004; 43: 36-40.

18. Verlohren S, Dubrovska G, Tsang SY, Essin K, Luft FC, Huang $Y$, et al. Visceral periadventitial adipose tissue regulates arterial tone of mesenteric arteries. Hypertension 2004; 44: 271-276.

19. Forstermann $U$, Munzel $T$. Endothelial nitric oxide synthase in vascular disease: from marvel to menace. Circulation 2006; 113: 1708-1714.

20. Akamine EH, Kawamoto EM, Scavone C, Nigro D, Carvalho $\mathrm{MH}$, de Cassia AT, et al. Correction of endothelial dysfunction in diabetic female rats by tetrahydrobiopterin and chronic insulin. J Vasc Res 2006; 43: 309-320.

21. Lobato NS, Filgueira FP, Akamine EH, Davel AP, Rossoni LV, Tostes RC, et al. Obesity induced by neonatal treatment with monosodium glutamate impairs microvascular reactivity in adult rats: role of $\mathrm{NO}$ and prostanoids. Nutr Metab Cardiovasc Dis 2011; 21: 808-816.

22. Dantas AP, Franco MC, Silva-Antonialli MM, Tostes RC, 
Fortes ZB, Nigro D, et al. Gender differences in superoxide generation in microvessels of hypertensive rats: role of NAD(P)H-oxidase. Cardiovasc Res 2004; 61: 22-29.

23. Serpillon S, Floyd BC, Gupte RS, George S, Kozicky M, Neito $\mathrm{V}$, et al. Superoxide production by $\mathrm{NAD}(\mathrm{P}) \mathrm{H}$ oxidase and mitochondria is increased in genetically obese and hyperglycemic rat heart and aorta before the development of cardiac dysfunction. The role of glucose-6-phosphate dehydrogenase-derived NADPH. Am J Physiol Heart Circ Physiol 2009; 297: H153-H162.

24. Akamine EH, Urakawa TA, de Oliveira MA, Nigro D, de Carvalho MH, de Cassia AT, et al. Decreased endotheliumdependent vasodilation in diabetic female rats: role of prostanoids. J Vasc Res 2006; 43: 401-410.

25. Traupe T, Lang M, Goettsch W, Munter K, Morawietz H, Vetter $\mathrm{W}$, et al. Obesity increases prostanoid-mediated vasoconstriction and vascular thromboxane receptor gene expression. J Hypertens 2002; 20: 2239-2245.

26. Tostes RC, David FL, Carvalho MH, Nigro D, Scivoletto $\mathrm{R}$, Fortes ZB. Gender differences in vascular reactivity to endothelin-1 in deoxycorticosterone-salt hypertensive rats. J Cardiovasc Pharmacol 2000; 36: S99-S101.

27. Mather KJ, Mirzamohammadi B, Lteif A, Steinberg HO, Baron AD. Endothelin contributes to basal vascular tone and endothelial dysfunction in human obesity and type 2 diabetes. Diabetes 2002; 51: 3517-3523.

28. Gao YJ. Dual modulation of vascular function by perivascular adipose tissue and its potential correlation with adiposity/ lipoatrophy-related vascular dysfunction. Curr Pharm Des 2007; 13: 2185-2192.

29. Stern N, Marcus Y. Perivascular fat: innocent bystander or active player in vascular disease? J Cardiometab Syndr 2006; 1: 115-120.

30. Lohn M, Dubrovska G, Lauterbach B, Luft FC, Gollasch M, Sharma AM. Periadventitial fat releases a vascular relaxing factor. FASEB J 2002; 16: 1057-1063.

31. Gao YJ, Holloway AC, Zeng ZH, Lim GE, Petrik JJ, Foster $W G$, et al. Prenatal exposure to nicotine causes postnatal obesity and altered perivascular adipose tissue function. Obes Res 2005; 13: 687-692.

32. Ma L, Ma S, He H, Yang D, Chen X, Luo Z, et al. Perivascular fat-mediated vascular dysfunction and remodeling through the AMPK/mTOR pathway in high-fat diet-induced obese rats. Hypertens Res 2010; 33: 446-453.

33. Gao YJ, Takemori K, Su LY, An WS, Lu C, Sharma AM, et al. Perivascular adipose tissue promotes vasoconstriction: the role of superoxide anion. Cardiovasc Res 2006; 71: 363373.

34. Kelley DE, Kuller LH, McKolanis TM, Harper P, Mancino J, Kalhan S. Effects of moderate weight loss and orlistat on insulin resistance, regional adiposity, and fatty acids in type 2 diabetes. Diabetes Care 2004; 27: 33-40.

35. Goldstein DJ. Beneficial health effects of modest weight loss. Int J Obes Relat Metab Disord 1992; 16: 397-415.

36. Mykkanen L, Haffner SM, Ronnemaa T, Bergman RN, Laakso M. Low insulin sensitivity is associated with clustering of cardiovascular disease risk factors. Am J Epidemiol 1997; 146: 315-321.

37. Pessin JE, Saltiel AR. Signaling pathways in insulin action: molecular targets of insulin resistance. J Clin Invest 2000; 106: 165-169.

38. Potenza MA, Marasciulo FL, Chieppa DM, Brigiani GS,
Formoso G, Quon MJ, et al. Insulin resistance in spontaneously hypertensive rats is associated with endothelial dysfunction characterized by imbalance between $\mathrm{NO}$ and ET-1 production. Am J Physiol Heart Circ Physiol 2005; 289: H813-H822.

39. Saad MF, Rewers M, Selby J, Howard G, Jinagouda S, Fahmi S, et al. Insulin resistance and hypertension: the Insulin Resistance Atherosclerosis study. Hypertension 2004; 43: 1324-1331.

40. Fortes ZB, Garcia LJ, Scivoletto R. Vascular reactivity in diabetes mellitus: possible role of insulin on the endothelial cell. Br J Pharmacol 1984; 83: 635-643.

41. Sartoretto JL, Melo GA, Carvalho MH, Nigro D, Passaglia RT, Scavone C, et al. Metformin treatment restores the altered microvascular reactivity in neonatal streptozotocininduced diabetic rats increasing NOS activity, but not NOS expression. Life Sci 2005; 77: 2676-2689.

42. Rastelli VM, Akamine EH, Oliveira MA, Nigro D, Passaglia $\mathrm{RC}$, Carvalho $\mathrm{MH}$, et al. Influence of insulin on the microvascular response to inflammatory mediators in neonatal streptozotocin diabetic rats. Inflamm Res 2005; 54: 173-179.

43. Laakso M, Edelman SV, Brechtel G, Baron AD. Decreased effect of insulin to stimulate skeletal muscle blood flow in obese man. A novel mechanism for insulin resistance. J Clin Invest 1990; 85: 1844-1852.

44. Steinberg HO, Chaker H, Leaming R, Johnson A, Brechtel $G$, Baron AD. Obesity/insulin resistance is associated with endothelial dysfunction. Implications for the syndrome of insulin resistance. J Clin Invest 1996; 97: 2601-2610.

45. Tirupattur PR, Ram JL, Standley PR, Sowers JR. Regulation of $\mathrm{Na}^{+}, \mathrm{K}^{+}$-ATPase gene expression by insulin in vascular smooth muscle cells. Am J Hypertens 1993; 6: 626-629.

46. Zemel MB, Johnson BA, Ambrozy SA. Insulin-stimulated vascular relaxation. Role of $\mathrm{Ca}^{2+}$-ATPase. Am J Hypertens 1992; 5: 637-641.

47. Reaven GM, Lithell H, Landsberg L. Hypertension and associated metabolic abnormalities - the role of insulin resistance and the sympathoadrenal system. N Engl J Med 1996; 334: 374-381.

48. Esler M, Straznicky N, Eikelis N, Masuo K, Lambert G, Lambert $E$. Mechanisms of sympathetic activation in obesityrelated hypertension. Hypertension 2006; 48: 787-796.

49. Wofford MR, Anderson DC Jr, Brown CA, Jones DW, Miller $\mathrm{ME}$, Hall JE. Antihypertensive effect of alpha- and betaadrenergic blockade in obese and lean hypertensive subjects. Am J Hypertens 2001; 14: 694-698.

50. Carlyle M, Jones OB, Kuo JJ, Hall JE. Chronic cardiovascular and renal actions of leptin: role of adrenergic activity. Hypertension 2002; 39: 496-501.

51. Eikelis N, Schlaich M, Aggarwal A, Kaye D, Esler M. Interactions between leptin and the human sympathetic nervous system. Hypertension 2003; 41: 1072-1079.

52. Rahmouni K, Morgan DA, Morgan GM, Liu X, Sigmund CD, Mark AL, et al. Hypothalamic PI3K and MAPK differentially mediate regional sympathetic activation to insulin. J Clin Invest 2004; 114: 652-658.

53. Rahmouni K, Haynes WG, Morgan DA, Mark AL. Role of melanocortin-4 receptors in mediating renal sympathoactivation to leptin and insulin. J Neurosci 2003; 23: 59986004.

54. Bulow J, Madsen J, Astrup A, Christensen NJ. Vasoconstrictor effect of high FFA/albumin ratios in adipose tissue in vivo. 
Acta Physiol Scand 1985; 125: 661-667.

55. Poykko SM, Kellokoski E, Horkko S, Kauma H, Kesaniemi YA, Ukkola O. Low plasma ghrelin is associated with insulin resistance, hypertension, and the prevalence of type 2 diabetes. Diabetes 2003; 52: 2546-2553.

56. Iwashima Y, Katsuya T, Ishikawa K, Ouchi N, Ohishi M, Sugimoto $\mathrm{K}$, et al. Hypoadiponectinemia is an independent risk factor for hypertension. Hypertension 2004; 43: 13181323.

57. Guimaraes S, Moura D. Vascular adrenoceptors: an update. Pharmacol Rev 2001; 53: 319-356.

58. Tesfamariam B, Weisbrod RM, Cohen RA. Cyclic GMP modulators on vascular adrenergic neurotransmission. J Vasc Res 1992; 29: 396-404.

59. Loesch A, Maynard KI, Burnstock G. Calcitonin gene-related peptide- and neuropeptide Y-like immunoreactivity in endothelial cells after long-term stimulation of perivascular nerves. Neuroscience 1992; 48: 723-726.

60. Coutinho GC, Durieu-Trautmann O, Strosberg AD, Couraud PO. Catecholamines stimulate the IFN-gamma-induced class II MHC expression on bovine brain capillary endothelial cells. J Immunol 1991; 147: 2525-2529.

61. Born GV. Recent evidence for the involvement of catecholamines and of macrophages in atherosclerotic processes. Ann Med 1991; 23: 569-572.

62. Rahmouni K, Mark AL, Haynes WG, Sigmund CD. Adipose depot-specific modulation of angiotensinogen gene expression in diet-induced obesity. Am J Physiol Endocrinol Metab 2004; 286: E891-E895.

63. Barton M, Carmona R, Morawietz H, d'Uscio LV, Goettsch $\mathrm{W}$, Hillen $\mathrm{H}$, et al. Obesity is associated with tissue-specific activation of renal angiotensin-converting enzyme in vivo: evidence for a regulatory role of endothelin. Hypertension 2000; 35: 329-336.

64. Engeli S, Bohnke J, Gorzelniak K, Janke J, Schling P, Bader $\mathrm{M}$, et al. Weight loss and the renin-angiotensin-aldosterone system. Hypertension 2005; 45: 356-362.

65. Tuck ML, Sowers J, Dornfeld L, Kledzik G, Maxwell M. The effect of weight reduction on blood pressure, plasma renin activity, and plasma aldosterone levels in obese patients. $N$ Engl J Med 1981; 304: 930-933.

66. Fliser D, Dikow R, Demukaj S, Ritz E. Opposing effects of angiotensin II on muscle and renal blood flow under euglycemic conditions. J Am Soc Nephrol 2000; 11: 2001-2006.

67. Folli F, Kahn CR, Hansen H, Bouchie JL, Feener EP. Angiotensin II inhibits insulin signaling in aortic smooth muscle cells at multiple levels. A potential role for serine phosphorylation in insulin/angiotensin II crosstalk. J Clin Invest 1997; 100: 2158-2169.
68. Luscher TF. Endothelial dysfunction: the role and impact of the renin-angiotensin system. Heart 2000; 84 (Suppl 1): $\mathrm{i} 20-\mathrm{i} 22$.

69. Nunes VW, Fortes ZB, Nigro D, Carvalho MH, Zorn TM, Scivoletto R. Influence of enalapril on the endothelial function of DOCA-salt hypertensive rats. Gen Pharmacol 2000; 34: 117-125.

70. Watanabe S, Tagawa T, Yamakawa K, Shimabukuro M, Ueda S. Inhibition of the renin-angiotensin system prevents free fatty acid-induced acute endothelial dysfunction in humans. Arterioscler Thromb Vasc Biol 2005; 25: 2376-2380.

71. Zhao W, Swanson SA, Ye J, Li X, Shelton JM, Zhang W, et al. Reactive oxygen species impair sympathetic vasoregulation in skeletal muscle in angiotensin II-dependent hypertension. Hypertension 2006; 48: 637-643.

72. Welch WJ. Angiotensin II-dependent superoxide: effects on hypertension and vascular dysfunction. Hypertension 2008; 52: 51-56.

73. Pagotto U, Marsicano G, Cota D, Lutz B, Pasquali R. The emerging role of the endocannabinoid system in endocrine regulation and energy balance. Endocr Rev 2006; 27: 73100.

74. Bluher M, Engeli S, Kloting N, Berndt J, Fasshauer M, Batkai $\mathrm{S}$, et al. Dysregulation of the peripheral and adipose tissue endocannabinoid system in human abdominal obesity. Diabetes 2006; 55: 3053-3060.

75. Cote M, Matias I, Lemieux I, Petrosino S, Almeras N, Despres JP, et al. Circulating endocannabinoid levels, abdominal adiposity and related cardiometabolic risk factors in obese men. Int J Obes 2007; 31: 692-699.

76. Randall MD, Harris D, Kendall DA, Ralevic V. Cardiovascular effects of cannabinoids. Pharmacol Ther 2002; 95: 191202.

77. Lake KD, Martin BR, Kunos G, Varga K. Cardiovascular effects of anandamide in anesthetized and conscious normotensive and hypertensive rats. Hypertension 1997; 29: 1204-1210.

78. Gardiner SM, March JE, Kemp PA, Bennett T. Complex regional haemodynamic effects of anandamide in conscious rats. Br J Pharmacol 2002; 135: 1889-1896.

79. Pacher P, Batkai S, Kunos G. Cardiovascular pharmacology of cannabinoids. Handb Exp Pharmacol 2005; 599-625.

80. Wheal AJ, Bennett T, Randall MD, Gardiner SM. Cardiovascular effects of cannabinoids in conscious spontaneously hypertensive rats. Br J Pharmacol 2007; 152: 717-724.

81. Batkai S, Pacher P, Osei-Hyiaman D, Radaeva S, Liu J, Harvey-White $\mathrm{J}$, et al. Endocannabinoids acting at cannabinoid-1 receptors regulate cardiovascular function in hypertension. Circulation 2004; 110: 1996-2002. 